\title{
High-Temperature Environmental Protection Metal Material 3D Printing Equipment Development and Process Research
}

\author{
Jiaofei Huo and Guangpeng Zhang (i) \\ School of Mechanical and Precision Instrument Engineering, Xi'an University of Technology, Xi'an 710048, Shaanxi, China \\ Correspondence should be addressed to Guangpeng Zhang; 20060005@xijing.edu.cn
}

Received 15 May 2021; Revised 17 June 2021; Accepted 15 July 2021; Published 26 July 2021

Academic Editor: Wei Liu

Copyright (C) 2021 Jiaofei Huo and Guangpeng Zhang. This is an open access article distributed under the Creative Commons Attribution License, which permits unrestricted use, distribution, and reproduction in any medium, provided the original work is properly cited.

\begin{abstract}
At present, 3D printing technology is becoming more and more popular, but the traditional learning method has some limitations. The price of 3D printing equipment is expensive, and there are some security risks in the process of learning operation. This paper mainly introduces the development and process research of high-temperature environmental protection metal 3D printing equipment and realizes the design of $3 \mathrm{D}$ printing equipment combined with virtual reality technology. In this paper, the whole system of 3D printing equipment is designed and built. The function of motion platform and substrate in mechanical system is analyzed, and the detailed structure design is carried out; the control principle of control system including motion control system and temperature control system is introduced in detail, and the corresponding design and construction work is carried out. In this paper, the pure tin wire with low melting point was used as the experimental material, and the mechanical properties and microstructure of the metal tin forming parts were analyzed. On the basis of tin formation experiment, metal deposition experiment and metal forming error experiment were carried out with $\mathrm{H} 65$ high melting copper wire as the raw material. The experimental results show that when the printing speed is $35 / \mathrm{mm}$, the dimensional accuracy of the products is high; the microhardness of the printed tin is close to that of the original material, the surface hardness is $12.50 \mathrm{HV}_{0.05}$, and that of the copper alloy is $14.31 \mathrm{HV}_{0.05}$; the tensile strength of tin wire after melt deposition is slightly reduced after tensile test for the machined tin parts, the ultimate tensile strength of the first group of specimens is reduced by $1.58 \%$, and that of the second group is reduced by $0.74 \%$. This paper combines virtual reality technology with 3D printing technology and develops 3D printing equipment for hightemperature environmental protection metal using virtual reality technology. The forming and printing performance of the device is analyzed theoretically and experimentally. The experimental results verify the feasibility of the system and the practicability of the device.
\end{abstract}

\section{Introduction}

With the in-depth study of manufacturing industry, innovation and product development cycle has become the main contradiction of the product. People put forward rapid prototyping technology, trying to shorten the development cycle and improve the competitiveness of products. 3D printing technology is a kind of rapid prototyping technology; that is, based on the idea of discretization, using plastic or powdered metal as raw materials, using printing equipment to manufacture materials layer by layer and accumulate layer by layer, and finally forming three-dimensional objects [1]. 3D printing combines digital model technology, control electronics technology, information technology, material science and chemistry, and many other advanced technologies, known as the core technology of the third industrial revolution. Compared with the traditional processing methods such as turning, milling, planning, and grinding, 3D printing is produced and manufactured in the form of addition, which has the characteristics of green environmental protection and is conducive to the manufacture of complex configuration items. It is widely used in automobile, aviation, aerospace, medical, education, electronic products, and other fields. At present, there are a variety of technologies in the field of $3 \mathrm{D}$ printing at home and abroad, and the commercialized processes mainly 
include melt deposition molding, selective laser sintering, selective laser melting molding, UV curing molding, layered solid manufacturing, laser cladding deposition technology, etc. $[2,3]$. All 3D printing technologies are composed of three key factors: first, 3D printing and forming equipment; second, three-dimensional design and modeling of products; third, molding materials to meet product performance requirements. With the development of industrial technology, materials have become the key of 3D printing technology and also the bottleneck restricting the development of $3 \mathrm{D}$ printing technology. In recent years, the focus of 3D printing has gradually shifted to metal 3D printing. 3D metal printing technology uses high-energy beam as heat source to melt or powder refractory metal. According to the type of highenergy beam, metal 3D printing can be divided into selective electron beam casting (plane ion beam forming), direct metal laser sintering, selective laser casting, selective laser sintering, etc. The metal 3D printing technology with laser as the heat source is the most mature and widely used [4].

The research on metal $3 \mathrm{D}$ printing manufacturing technology started earlier in foreign countries. Since the early emergence of 3D printing technology, researchers have tried to use various postprocessing processes to process nonmetallic models based on rapid prototyping method to prepare the required metal parts. Murr and Johnson reviewed the development of metal 3D printing technology in the past few decades and found that technologies involving direct metal wire or powder deposition and powder bed fusion using laser and electron beam melting are developing continuously, but there is no big breakthrough in the printing technology of direct printing molten metal droplets [5]. Li et al. use 3D printing to produce highstrength metal abrasives. Through the screening of powder materials and preparation methods, the solution with excellent mechanical properties is selected for preparation. The density, hardness, and toughness of three kinds of metal materials are tested. The high-strength drill bit is successfully produced by using the metal abrasive tools manufactured by printing, which proves the feasibility of metal 3D printing technology, but they do not carry out the test. The printing test of their articles cannot be comprehensively analyzed [6]. Buchanan and Gardner believe that metal 3D printing provides a convenient manufacturing method for creating nonprismatic cross sections, openings, functional gradient elements, variable microstructure, and mechanical properties by controlling heating and cooling and thermal induced prestressing. High-temperature environmental protection metal 3D printing also requires more advanced calculation and analysis, structural design, and new verification thinking and pays more attention to inspection and performance testing [7].

This paper will mainly solve several core problems, such as reducing the manufacturing, operating and operating costs of relevant equipment, improving energy utilization, deposition speed, and molding accuracy, and build a group of new high-temperature environmental protection metal material processing equipment and rapid prototyping to provide high-quality and high-efficiency additive processing strategy. It is of great social significance to promote the market application of metal additive technology and promote the transformation and upgrading of traditional industries.

\section{Design of High-Temperature Environmental Protection Metal 3D Printing}

\subsection{Virtual Reality Technology}

2.1.1. Definition of Virtual Reality. Virtual reality (VR), also known as fantasy or spirit environment technology, is through computer hardware technology and image processing technology, so that users can realize a kind of perception of virtual environment through visual, auditory, tactile, olfactory, and other sensing means. Users visit the virtual environment with the help of unique output and input devices, and the virtual environment gives feedback to users, so that people feel as if they are in the virtual environment feeling and experience in real environment $[8,9]$.

The main characteristics of virtual reality system can be summarized into three aspects: immersion, interaction, and imagination. Immersion can make users fully feel the shock brought by the virtual space environment. VR helmets, glasses. and other virtual reality devices separate traditional video and use real-world vision to provide different images of the left and right sides of the eye, making objects have a three-dimensional sense. Interactivity refers to the interaction between user's action and virtual scene in the virtual world. Imagination refers to the fact that when users use virtual reality technology, with the help of virtual reality technology, the effect that reality does not exist is presented to the public, so that people can turn their imagination into reality and enhance their ability to understand and deal with problems [10].

2.1.2. Architecture of Virtual Reality. Virtual reality technology is a comprehensive technology which integrates computer graphics, sensor technology, interactive technology, and network technology. The most basic requirement of virtual reality technology is to realize real-time interaction with users [11]. Therefore, a basic virtual reality system is mainly composed of computer, input and output equipment, application software, and database:

(1) Computer is the carrier of virtual reality world and the core of the whole virtual world. The main work is responsible for the generation of virtual reality world and the processing of interactive information between users and virtual world. According to the complexity of the virtual world, the requirements of computer performance are not the same. When generating complex large-scale scenes, the amount of computation required is very large, which requires the computer to have high computational performance.

(2) The input and output device is the medium of interaction between computer and user. The input device is the interface for users to send instructions to the virtual world. Its function is to receive the 
instructions from the users and convert the user's actions into information and data input into the computer. According to different requirements and purposes, the input devices include space tracking locator, data glove, data clothing, etc.

The output device is the medium for virtual reality world to give feedback to users. Its function is to output the feedback information generated by computer to users through different sensory channels. In addition to the traditional display, the output devices include force feedback data glove, digital helmet, stereo surround sound headset, etc.

(3) Database is the repository of all relevant information in the virtual world, such as geometric model, physical model, and captured user action information in virtual reality environment. In the scene of virtual reality world, a large amount of information needs to be stored for use, which requires the database to manage this information.

(4) The software application in virtual reality system is the key to realize the virtual environment. Its specific task is to make the model in the virtual scene, to ensure the fluency of the direct interaction between people and the virtual environment, as well as the synthesis of sound and the positioning of space.

2.1.3. Development Trend of Virtual Reality Technology. At present, industries are increasingly dependent on the Internet, and people's demand for entertainment is also growing. In order to adapt to the development of the times, the continuous integration of virtual reality technology and art is needed. The rapid popularization of video applications has verified that the public's way of receiving information is no longer single, and the content required is also constantly enriched. It will be one of the development trends of virtual reality technology in the future to combine new technology and new equipment to subvert the public's cognitive boundary of information. Due to the unique advantages of virtual reality technology, it can go deep into all walks of life. In the process of virtualization, some traditional industries continue to bring forth new ones, and traditional industries have entered the era of great change [12]. With the vigorous development of virtual reality technology, it will also bring more new challenges to the traditional industrial chain. Various virtual reality derivatives formed by various industries have promoted this change to a certain extent.

\subsection{Basic Theory of $3 D$ Printing Technology}

2.2.1. Working Principle of 3D Printing Technology. 3D printing technology is also called rapid prototyping and manufacturing (RP or RP \& M) or additive manufacturing. It is a new manufacturing method compared with the traditional reduction manufacturing. The principle is to break the original concept of material processing. Instead of cutting the blank, the computer is used to establish the three- dimensional model of the product to be produced, and then it is layered. Each layer is used as the information unit of the product. Then, the $3 \mathrm{D}$ printer is used to manufacture layer by layer, and finally the solid model is completed $[13,14]$. In the whole $3 \mathrm{D}$ printing process, its core technologies include the following aspects.

(1) Building 3D digital model:

Digital model is the premise of printing process. For complex structure products, its model construction form is very important. At present, the mainstream $3 \mathrm{~d}$ design software can basically realize the design modeling of complex structure and then need to convert the digital model into printing information suitable for 3D printer recognition. The accuracy and scientificity of this information conversion play a decisive role in the printing quality of products.

(2) Printing process parameter selection:

For 3D printing process as an additive manufacturing method, printing materials are added to the printing model layer by layer, so there are strict requirements for printing path, printing speed, printing room temperature, and other process parameters. Process parameters directly affect the manufacturing accuracy and reliability of printed parts. Therefore, the selection of process parameters needs special research and testing to ensure the quality of printed products.

(3) Printing completes the subsequent processing:

Restricted by the performance of printing materials and the accuracy of printers, the surface roughness of models printed by printers developed at this stage cannot meet the requirements of products. Therefore, it is necessary to increase the process of improving the surface quality of products after printing. In addition, in order to improve the reliability of products, some printing products must be heattreated to eliminate the residual stress generated in the printing and cooling process. Under the current technical level, subsequent treatment is essential [15].

\subsubsection{Overview of Temperature Field and Stress Field Theory} in $3 D$ Printing Process

(1) Theoretical analysis of temperature field:

In the $3 \mathrm{D}$ printing process, with the application of heat source, the energy transfer of the model temperature field is nonlinear, and the laser heat source moves continuously according to the scanning line. Therefore, according to the energy conservation and Fourier law, the energy transfer process is a transient process, and the transfer process satisfies the following equation [16]:

$$
\frac{\partial}{\partial x}\left(k \frac{\partial T}{\partial x}\right)+\frac{\partial}{\partial y}\left(k \frac{\partial T}{\partial y}\right)+\frac{\partial}{\partial z}\left(k \frac{\partial T}{\partial z}\right)+\dot{q}=p c_{p} \frac{\partial T}{\partial t} .
$$


According to formula (1), time is the first-order differential, and the space is the second-order differential. Therefore, we need to provide an initial value for time and two initial values for space to obtain the solution of the above formula and obtain the specific distribution of temperature field. According to the theory of temperature field heat transfer, the boundary conditions to be applied can be roughly divided into the following three types $[17,18]$ :

The first method is to determine the temperature on all boundaries of an object, that is, when the surface temperature of the object is known and unchanged:

$$
\lambda \frac{\partial T}{\partial x} n_{x}+\lambda \frac{\partial T}{\partial y} n_{y}+\lambda \frac{\partial T}{\partial z} n_{z}=q_{s}(x, y, z, t) .
$$

The second is that the heat flux density of the object boundary is known:

$$
\lambda \frac{\partial T}{\partial a} n_{a}+\lambda \frac{\partial T}{\partial b} n_{b}+\lambda \frac{\partial T}{\partial c} n_{c}=q_{s}(a, b, c, t) .
$$

The third is that the heat transfer coefficient between the boundary and the surrounding objects is known:

$$
\lambda \frac{\partial T}{\partial x} n_{x}+\lambda \frac{\partial T}{\partial y} n_{y}+\lambda \frac{\partial T}{\partial z} n_{z}=h\left(T_{\infty}-T_{s}\right) .
$$

(2) Theoretical analysis of stress field:

In the process of $3 \mathrm{D}$ printing, the stress changes of materials are affected by various factors, so it is necessary to combine the temperature field theory with the stress field theory.

When the temperature of the object changes, the intermolecular force also changes, and the change of the molecular gap leads to the volume change and deformation of the object. When the body is not constrained, the thermal deformation can be expressed as [19-21]

$$
\varepsilon_{T}=\frac{\Delta L_{T}}{L_{0}}=a\left(T_{1}-T_{0}\right) .
$$

Due to the existence of thermal deformation, when the temperature of the object changes but it cannot deform freely, the original thermal deformation of the object cannot occur normally. If $\Delta L_{e}$ is used to represent the deformation amount of the object after being constrained, the deformation degree of the object is as follows:

$$
\varepsilon_{T}=\frac{\Delta L_{e}}{L_{0}}
$$

Since the object cannot deform itself after temperature change, its original deformation is reflected in the object, and the deformation rate can be expressed as follows:

$$
\varepsilon_{T}=\frac{\Delta L}{L_{0}}
$$

After the temperature changes, the amount of deformation inside the object exceeds the elastic limit. After the temperature returns to the initial value, the material cannot be restored to its original state, and then the residual stress will be generated inside the object. According to the deformation theory, the stress value and strain value of the object satisfy the following relationship:

$$
\begin{aligned}
& \left(\frac{\partial^{2} \varepsilon_{x}^{\prime}}{\partial y^{2}}+\frac{\partial^{2} \varepsilon_{y}^{\prime}}{\partial x^{2}}-\frac{\partial^{2} \gamma_{x y}^{\prime}}{\partial x \partial y}\right)+\left(\frac{\partial^{2} \varepsilon_{x}^{\prime \prime}}{\partial y^{2}}+\frac{\partial^{2} \varepsilon_{y}^{\prime \prime}}{\partial x^{2}}-\frac{\partial^{2} \gamma_{x y}^{\prime \prime}}{\partial x \partial y}\right)=0, \\
& R=-\left(\frac{\partial^{2} \varepsilon_{x}^{\prime \prime}}{\partial y^{2}}+\frac{\partial^{2} \varepsilon_{y}^{\prime \prime}}{\partial x^{2}}-\frac{\partial^{2} \gamma_{x y}^{\prime \prime}}{\partial x \partial y}\right) .
\end{aligned}
$$

When $R=0$, it means that there is elastic sex inside the object and it can be freely retracted and restored to its original state. $R \neq 0$ indicates that there is residual stress in the body.

\subsection{Design of the 3D Printing System}

2.3.1. Overall Design of the System. The overall design of 3D printing system mainly includes four parts, the main functions of each part are as follows:

(1) Virtual Reality Interactive Device. Use virtual reality to display hardware and interact with elements in unity

(2) Printer Operation Control System. Realize the control of printer printing, leveling, startup, and cooling

(3) User Interface Control System. Set the parameters of the printer and realize the state control

(4) Model Analysis and Calculation System. Comprehensively analyze the model to be printed, realize the calculation of the simple base support of the model, and calculate the running track of the printing nozzle [22]

The system realizes interaction through virtual reality equipment and then enters into the user interface to realize control and setting. After completing a series of operations, it realizes model analysis and calculation and determines the trajectory of printing nozzle in each layer of printing process, so as to realize printing. According to the coordinate system used, 3D printer can be divided into polar coordinate system and Cartesian coordinate system, according to the material forming principle. It can be divided into powder binder, sintering and melting, lamination manufacturing, melting deposition molding technology, polymer polymerization reaction, etc. The system designed in this paper is based on the Cartesian coordinate system, which can move in the straight direction of XYZ three axes. Each axis adopts small stepping motor with high precision and good precision and then uses subdivision control stepping motor to make its accuracy reach about $1 \mathrm{~mm}$. The $x$-axis and $y$-axis adopt synchronous belt, which can accurately and quickly locate 
according to the axial direction, and the $z$-axis adopts the screw for precise positioning. The main principle of material forming is deposition modeling technology. Simply put, the hot-melt plastic is heated at the designated position, then the thinner plastic wire is extruded, and finally the $3 \mathrm{D}$ object is made by depositing the plastic wire.

\subsubsection{Design and Construction of the Mechanical System.} In essence, $3 \mathrm{D}$ printing equipment is a three-axis $\mathrm{CNC}$ machine tool. The three-axis motion system is the key executive system of 3D printer mechanical system. The reasonable design of transmission structure and motion mode has a very important impact on the accuracy and efficiency of printing process, which will eventually affect the quality of printed products [23]. Therefore, a reasonable design scheme should be adopted for the three-axis motion system.

The motion platform of $3 \mathrm{D}$ printing equipment is composed of $X, Y, Z$ three-axis motion platform, in which $x$ axis and $y$-axis coordinate to complete the horizontal movement in xoy plane of substrate, and deposition is mainly realized by the movement of these two axes; $z$-axis controls the up and down movement of the nozzle, controls the layer thickness, and completes the load-bearing work of the whole nozzle. The movement of the three axes is controlled by the stepping motor. At the same time, two limit switches are installed on each axis, and the sensing distance is $2 \mathrm{~mm}$. It ensures the safety of the platform in the process of motion. Since all the deposition work in the molding process is realized by the movement of the moving platform, the accuracy and stability of the motion platform are the key to ensure the deposition quality. Therefore, the ball screw is selected as the transmission mechanism of the three motion platforms to ensure the stability of the molding process [24]. Among them, the lead of $x$-axis, $y$-axis, and $z$-axis is $10 \mathrm{~mm}$, $10 \mathrm{~mm}$, and $10 \mathrm{~mm}$ respectively, and the stroke of three motion platforms is $350 \mathrm{~mm}, 200 \mathrm{~mm}$, and $250 \mathrm{~mm}$, respectively.

2.3.3. Design and Construction of the Control System. The whole system control framework of the equipment is as follows:

(1) Main control module: this paper uses Mega2560 microcontroller as the lower computer of the control system.

(2) Motor drive module: in this paper, five stepper motors are used to realize the drive function of the control system. The $x$-axis and $y$-axis select one stepper motor to realize the precise positioning of the extrusion nozzle; the $z$-axis uses two stepper motors to drive the working platform to move up and down; the wire feeding mechanism also uses a stepper motor to drive the molten silk material out through the rotation of the stepping motor.

(3) Temperature control module: the module mainly heats the hot bed and extrusion nozzle and collects and feeds back the temperature. The heating temperature of the hot bed ensures that the silk material can stick to the working platform, while the temperature of the extrusion nozzle should ensure that the silk material can melt and print. The real-time temperature feedback ensures that the working environment is in a constant temperature state.

(4) Serial communication module: it is mainly used for data communication between upper computer and lower computer, receiving printing data, controlling command, monitoring printing process, and adjusting printing parameters timely according to feedback results.

(5) Data communication module: this module mainly includes display screen and SD card data reading. The display screen shows the printing status of the printing equipment, including printing speed, printing temperature, printing completion, etc.; the $\mathrm{SD}$ card is responsible for receiving and transferring $\mathrm{G}$ code in the printing process of $3 \mathrm{D}$ model.

In the whole $3 \mathrm{D}$ printing process, the microcontroller controls and sends out instructions, the stepper motor executes the received instructions, and the sensor monitors the temperature of the feedback nozzle and working platform in real time, forming a virtuous closed-loop control system [25].

\section{Experimental Materials and Methods}

3.1. Experimental Materials. The experimental material tin is widely used in various fields, including electronics, information, metallurgy, machinery, and so on. Because the metal tin has a low melting point, tin is used as the experimental material to debug the basic functions of metal 3D printing equipment based on electromagnetic induction heating technology.

Copper, which has conductivity, thermal conductivity, and ductility, plays an important role in human development. $\mathrm{H} 65$ brass is a kind of common brass which is widely used. It has good mechanical cutting performance, can be used as solder for brazing and welding, and has good mechanical properties. It is usually used as raw material for pin nut.

The raw materials used in the experiment are pure tin wire and brass wire, and the wire diameter is $4 \mathrm{~mm}$.

As shown in Tables 1 and 2, the chemical compositions of pure tin wire and brass wire are listed.

3.2. Experimental Methods. In this paper, we collect the traffic data in the morning and evening of the same road section in the city. The data collection time is the first three days of the experimental simulation, and the data sampling interval is 5 minutes. This paper randomly selects the monitoring data of six sensors in the traffic section of the city. From the morning peak time (7:00-10:00) and the 
TABle 1: Chemical composition of pure tin.

\begin{tabular}{lccc}
\hline Element & Sn & Mn \\
\hline Content & 99.1 & 0.9 \\
\hline
\end{tabular}

TABLE 2: Chemical composition of H65 brass.

\begin{tabular}{cccccccc}
\hline Element & $\mathrm{Cu}$ & $\mathrm{Pb}$ & $\mathrm{P}$ & $\mathrm{Sb}$ & $\mathrm{Bi}$ & $\mathrm{Fe}$ & $\mathrm{Zn}$ \\
\hline Content & $62.7-68$ & $\geq 0.01$ & $\geq 0.01$ & $\geq 0.005$ & $\geq 0.003$ & $\geq 0.05$ & Allowance \\
\hline
\end{tabular}

evening peak time (17:00-20:00), each sensor collects and outputs the traffic data every 5 minutes and adds the daily weather data.

\subsection{Experimental Evaluation Index}

3.3.1. Performing Morphology Experiment. In this study, VK-X200K laser confocal microscope was used to synthesize the depth of field on the surface of the molded part, and the surface morphology, surface roughness, and weld bead overlap were observed.

\subsubsection{Mechanical Property Test}

(1) Microhardness:

In this experiment, Vickers hardness is used as the hardness test standard. The sample with high density and uniform microstructure is selected for measurement. The upper surface and section of the molded part are selected as the measurement position. After each measurement, after removing the load, the hardness value is calculated by measuring the diamond diagonal length of the measurement point on the sample surface. The calculation formula is shown in the following formula:

$$
H_{v}=1.8544 \frac{P_{\max }}{d^{2}} .
$$

(2) Tensile property:

In this study, MTS (SANS) cmt5105 microcomputer controlled electronic testing machine is used to test, analyze, and study the static mechanical properties of metal, nonmetal, and composite materials, such as tensile strength, compressive strength, bending strength, modulus, and other parameters under different speed conditions, and according to national standards, ISO and ASTM, and other international standards for testing and data determination.

(3) Microstructure examination:

This experiment is to compare and analyze the metallographic structure of raw materials and formed samples. Therefore, the samples of wire and molded samples are taken and numbered in order, and then the samples are inlaid and the sealing of inlays is checked. The samples with good sealing performance were selected and analyzed by laser confocal microscope and Fei quanta 250 FEG scanning electron microscope.

\section{Experimental Results}

4.1. Printing Error Experiment of Metal Materials. In the experimental stage, in order to facilitate the measurement of product size accuracy, standard spline is used to test. During the measurement, the dimensions of $X, Y$, and $Z$ directions are mainly measured. The length measured in $X$ direction is the total length of spline, $Y$ direction is the original width of parallel length of spline, and $Z$ direction is the thickness of spline. The original size of standard spline: $X=98 \mathrm{~mm}$, $Y=15 \mathrm{~mm}, Z=3 \mathrm{~mm}$.

As shown in Figure 1, according to the comparative analysis results of multiple groups of parameters, when the layer thickness is $0.15 \mathrm{~mm}$, the printing product has higher accuracy, and when the thickness of each layer is smaller, the total error of stacking molding is relatively small. When the printing speed is fast, the error of the product will increase. From the measurement results, when the printing speed is $35 / \mathrm{mm}$, the dimensional accuracy of the products is higher.

4.2. Microhardness Test of Metal Materials. As shown in Figure 2, the hardness of the original tin material is $14.82 \mathrm{HV}_{0.05}$. After printing, the hardness fluctuates in the range of $11.70 \mathrm{HV}_{0.05}-12.50 \mathrm{HV}_{0.05}$, which is not much lower than that of the original tin material, indicating that the surface microhardness value of the formed parts after this process can basically reach the hardness value of the original material, reaching the casting process level. The hardness of the original copper is $16.20 \mathrm{HV}_{0.05}$, and the hardness after printing is $12.96 \mathrm{HV}_{0.05}-14.31 \mathrm{HV}_{0.05}$, which is $11.73 \%$ lower than that of the original copper, indicating that the surface microhardness of the copper formed by this process cannot reach the hardness value of the original material. From the metal materials formed after printing, it can be seen that the grains of the original copper wire are slender strips, and the grains of the molded parts are multilateral, and the grain size is larger than that of the original copper wire. At the same time, according to hall Petch formula, in a certain range, the smaller the grain size $D$, the greater the microhardness $\mathrm{HV}$ of the material. This also explains why the hardness of the printed parts becomes smaller.

4.3. Testing of Tensile Properties of Metal Materials. As shown in Figures 3 and 4, the ultimate tensile strength of the tin wire after melt deposition is slightly reduced. Compared 


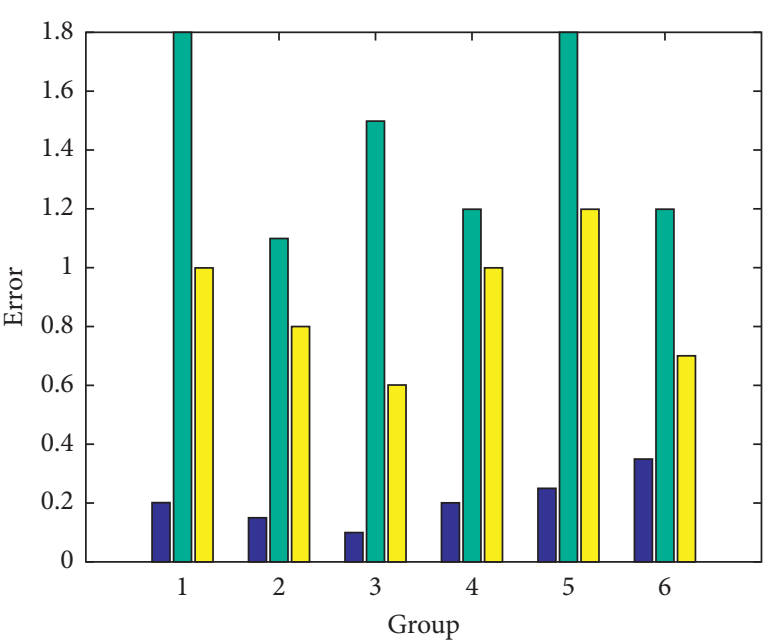

$\square X$
$\square Y \%$
$\square Z \%$

Figure 1: Print error results.

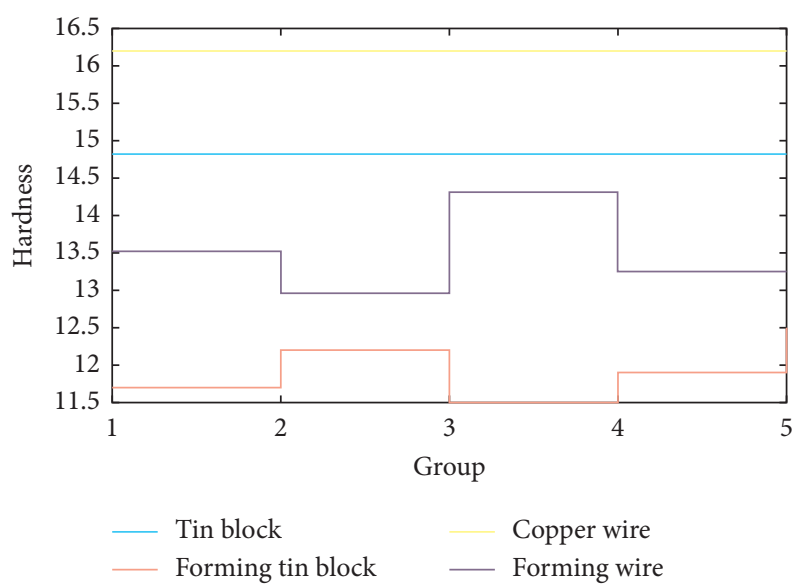

FIgURE 2: Hardness comparison of metal materials before and after molding.

with the machined tin parts, the ultimate tensile strength of the first group of samples is reduced by $1.58 \%$, and that of the second group of samples is reduced by $0.74 \%$. There are obvious bonding surfaces between the layers of the third group of samples, and the interlayer bonding strength is not high, showing multiple abrupt changes in the stress-strain curve. Value exists. It can be inferred from the test results that the reduction of ultimate tensile strength of the molded parts is mainly due to the influence of interlayer bonding properties. The metal 3D printing equipment based on electromagnetic induction heating technology designed in this paper will slide when the bonding interface between layers is subjected to a certain tensile force during the drawing process. Therefore, if the interlayer bonding is not firm, the overall mechanical properties of the formed parts will slightly decrease.

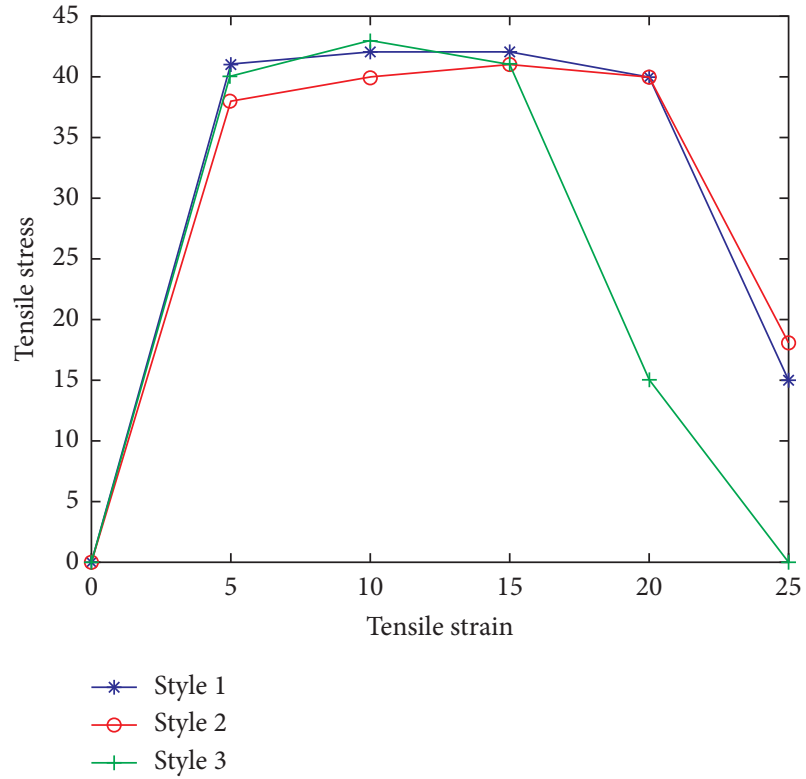

Figure 3: Pattern stress-strain curve.

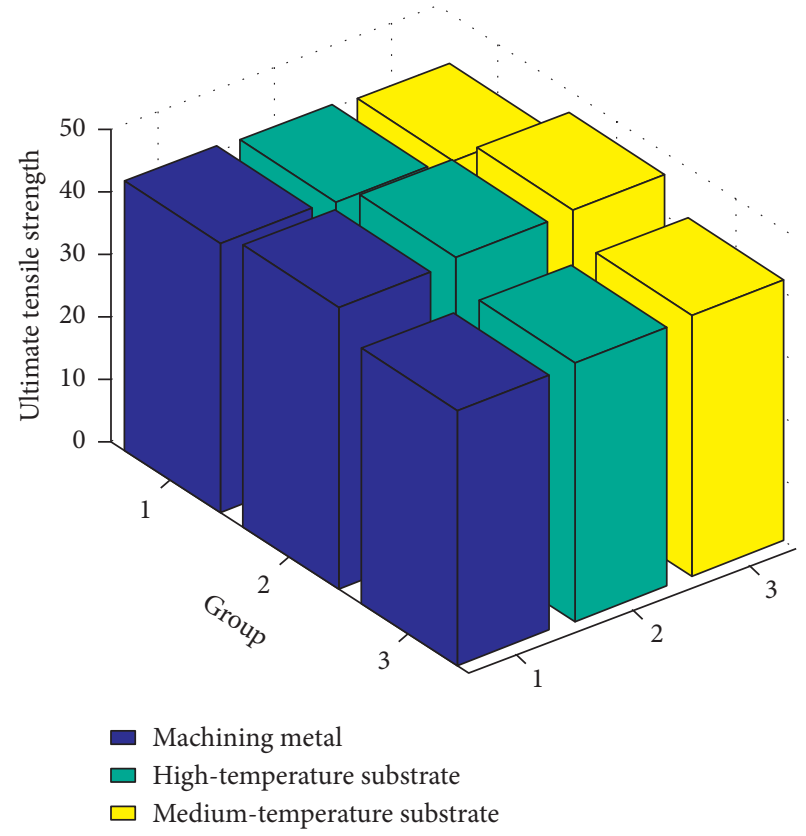

FIGURE 4: Ultimate tensile strength of tensile specimens.

\section{Conclusions}

3D printing technology has a decade of development, although it is widely used in the industrial field and has certain achievements. However, due to the rapid development of modern software technology and the Internet, the improvement of 3D printer has attracted much attention. The processing method of 3D printing technology is to accumulate layer by layer, without any mechanical processing and mold. All shape parts can be generated directly through computer graphics data, so as to shorten product development cycle, 
improve product productivity, and effectively reduce production costs.

In this paper, the design of $3 \mathrm{D}$ printing experience system in virtual reality technology is analyzed. The research results can be used for 3D printer printing design of melt deposition molding and also can be used for the development of virtual printing system of 3D printing technology. In this paper, the overall scheme design of 3D printer is carried out. The motion mode of electromagnetic induction nozzle and printing table, system composition, and design/selection principle of each subsystem are determined. The mechanical structure and electrical system of the equipment are optimized. The feasibility of base metal deposition process is verified by using low melting point pure tin wire and high melting point copper alloy wire as experimental materials. The mechanical properties of the formed parts were studied in terms of strength and microstructure. By testing the system designed in this paper, it shows that the system can provide intuitive, safe, and efficient experience platform for people.

There are many deficiencies in this study. This paper only studies the melting deposition of tin and copper, and it needs to study the properties of many kinds of metal wire materials in the future. It is necessary to optimize the structure of the induction nozzle based on high-temperature environmental protection metal 3D printing equipment, so as to increase the molding speed and improve the molding quality.

\section{Data Availability}

The data that support the findings of this study are available from the corresponding author upon reasonable request.

\section{Conflicts of Interest}

The authors declare no conflicts of interest.

\section{References}

[1] B. G. Compton and J. A. Lewis, "3D-printing of lightweight cellular composites," Advanced Materials, vol. 26, no. 34, pp. 5930-5935, 2015.

[2] S. Hong, D. Sycks, H. F. Chan et al., “3D printing: 3D printing of highly stretchable and tough hydrogels into complex, cellularized structures (adv. Mater. 27/2015)," Advanced Materials, vol. 27, no. 27, p. 4034, 2015.

[3] J. Edgar and S. Tint, "Additive manufacturing technologies: 3D printing, rapid prototyping, and direct digital manufacturing," Johnson Matthey Technology Review, vol. 59, no. 3, pp. 193-198, 2015.

[4] M. Zarek, M. Layani, I. Cooperstein et al., "3D printing of shape memory polymers for flexible electronic devices," Advanced Materials, vol. 28, no. 22, p. 4166, 2015.

[5] L. E. Murr and W. L. Johnson, "3D metal droplet printing development and advanced materials additive manufacturing," Journal of Materials Research and Technology, vol. 6, no. 1, pp. 77-89, 2017.

[6] R. Li, Y. S. Kim, H. V. Tho, Y. J. Yum, W. J. Kim, and S. Y. Yang, "Additive manufacturing (AM) of piercing punches by the PBF method of metal 3D printing using mold steel powder materials," Journal of Mechanical Science and Technology, vol. 33, no. 2, pp. 809-817, 2019.

[7] C. Buchanan and L. Gardner, "Metal 3D printing in construction: a review of methods, research, applications, opportunities and challenges," Engineering Structures, vol. 180, no. 1, pp. 332-348, 2019.

[8] U. Ecke, L. Klimek, W. Müller, R. Ziegler, and W. Mann, "Virtual reality: preparation and execution of sinus surgery," Computer Aided Surgery, vol. 3, no. 1, pp. 45-50, 2015.

[9] P. H. Cosman, P. C. Cregan, C. J. Martin, and J. A. Cartmill, "Virtual reality simulators: current status in acquisition and assessment of surgical skills," ANZ Journal of Surgery, vol. 72, no. 1, pp. 30-34, 2015.

[10] E. Bastug, M. Bennis, M. Medard, and M. Debbah, “Toward interconnected virtual reality: opportunities, challenges, and enablers," IEEE Communications Magazine, vol. 55, no. 6, pp. 110-117, 2017.

[11] G. L. Nieder, J. N. Scott, and M. D. Anderson, "Using QuickTime virtual reality objects in computer-assisted instruction of gross anatomy: yorick-the VR Skull," Clinical Anatomy, vol. 13, no. 4, pp. 287-293, 2015.

[12] B. Riecke, H. Veen, and H. Bülthoff, "Visual homing is possible without landmarks: a path integration study in virtual reality," Presence: Teleoperators and Virtual Environments, vol. 11, no. 5, pp. 443-473, 2015.

[13] L. E. Murr, "A metallographic review of 3D printing/additive manufacturing of metal and alloy products and components," Metallography Microstructure \& Analysis, vol. 7, no. 3, pp. 1-30, 2018.

[14] L. J. Kumar, P. M. Pandey, and D. I. Wimpenny, "Metal powder based additive manufacturing technologies-business forecast," 3D Printing and Additive Manufacturing Technologies, vol. 10, pp. 105-118, 2019.

[15] P. Mellin, C. Jönsson, M. Åkermo et al., "Nano-sized byproducts from metal 3D printing, composite manufacturing and fabric production," Journal of Cleaner Production, vol. 139, no. 15, pp. 1224-1233, 2016.

[16] Z. Baoqing, M. I. Farid, Y. Shuo, C. Cong, and S. Zhang, "Finite element simulation, analysis and research on the influence of 3D printing parameters on forming precision," Recent Patents on Engineering, vol. 13, no. 4, pp. 448-454, 2019.

[17] Z.-D. Shan, Z. Guo, D. Du, and F. Liu, "Coating process of multi-material composite sand mold 3D printing," China foundry, vol. 14, no. 6, pp. 498-505, 2017.

[18] B. Hu, X. Duan, Z. Xing et al., "Improved design of fused deposition modeling equipment for $3 \mathrm{D}$ printing of highperformance PEEK parts," Mechanics of Materials, vol. 137, no. Oct., pp. 103139.1-103139.8, 2019.

[19] Y. Ju, L. Wang, H. Xie, G. Ma, Z. Zheng, and L. Mao, "Visualization and transparentization of the structure and stress field of aggregated geomaterials through 3D printing and photoelastic techniques," Rock Mechanics and Rock Engineering, vol. 50, no. 6, pp. 1383-1407, 2017.

[20] I. M. Cotabarren, S. Cruces, and C. A. Palla, "Extrusion 3D printing of nutraceutical oral dosage forms formulated with monoglycerides oleogels and phytosterols mixtures," Food Research International (Ottawa, Ont.), vol. 126, no. Dec, pp. 108676.1-108676.11, 2019.

[21] S. C. Park, R. Song, S. Kim, H. K. Kim, S.-H. Kim, and J. Lee, "Fabrication of artificial arteriovenous fistula and analysis of flow field and shear stress by using $\mu$-PIV technology," Journal of Mechanical Science and Technology, vol. 30, no. 12, pp. 5503-5511, 2016. 
[22] J. An, J. E. M. Teoh, R. Suntornnond, and C. K. Chua, "Design and $3 \mathrm{D}$ printing of scaffolds and tissues," Engineering, vol. 1, no. 2, pp. 261-268, 2015.

[23] R. J. Mobbs, M. Coughlan, R. Thompson, C. E. Sutterlin, and K. Phan, "The utility of 3D printing for surgical planning and patient-specific implant design for complex spinal pathologies: case report," Journal of Neurosurgery: Spine, vol. 26, no. 4 , pp. 513-518, 2017.

[24] H. J. Huang, G. D. Zhang, H. B. Ouyang et al., "[Internal fixation surgery planning for complex tibial plateau fracture based on digital design and 3D printing]," Journal of Southern Medical University, vol. 35, no. 2, pp. 218-222, 2015.

[25] A. Kantaros, N. Chatzidai, and D. Karalekas, "3D printingassisted design of scaffold structures," International Journal of Advanced Manufacturing Technology, vol. 82, no. 1-4, pp. 559-571, 2016. 